\title{
Surgical Palliative Drainage in Un-resectable Malignant Biliary Obstruction
}

Sanei $\mathbf{B}^{1}$, Kolahdouzan $\mathbf{M}^{2}$, Sheikhbahaei $\mathbf{S}^{3,5}$, Janbazi L4, Shahabi $\mathbf{S}^{5}$ and Rezaei MA ${ }^{5 *}$

${ }^{1}$ Department of hepatobiliary and pancreatic surgery, Isfahan University of Medical Sciences, Isfahan, Iran

${ }^{2}$ Department of Thoracic Surgery, Isfahan University of Medical Sciences, Isfahan, Iran

${ }^{3}$ Acquired Immunodeficiency Research Center, Isfahan University of Medical Sciences, Isfahan, Iran

${ }^{4}$ Department of Physical Medicine and Rehabilitation, Iran University of Medical Sciences, Tehran, Iran

${ }^{5}$ Department of General Surgery, Isfahan University of Medical Sciences, Isfahan, Iran

\begin{abstract}
Introduction: Tumor resection is the curative therapy in the patients with malignant obstruction and in nonoperable patients non-surgical palliative therapy, is recommended. These methods may not be successful in some cases because of the various reasons, so the surgical intervention is needed to eliminate biliary obstruction. The aim of this study is to introduce and evaluate a new method for drainage in the patients with un-resectable malignant obstruction in biliary system.
\end{abstract}

Method: This study included 21 patients with un-resectable tumor of biliary tract causing obstruction. After exploring the abdomen, segment II and III of liver will be dissected and then a part of segment III will be removed. In all of cases feeding tube will be put in the duct. Two to three biliary ducts will be specified; thus, feeding tube at least number 5 will be inserted inside the duct and guided through the liver so that it reaches the large ducts inside. A Roux arch will be created afterwards, and will be anastomosed to the liver capsule in parachute procedure. After operation patients will be monitored for the outbreak of cholangitis, anastomosis leakage, pruritus and the decrease of bilirubin level.

Results: The new method of surgery in patients with malignant obstruction of the biliary tract was exclusively palliative in all 21 cases. The 30 -day mortality in the study group was $14.3 \%(n=3 / 21)$. Pruritus was comparatively cured in the patients (85.7\%), and prevalence of cholangitis was decreased after the intervention (19\% to $14.3 \%$ ). Anastomosis was leaked in just one patient.

Conclusion: In patients with amalignant obstruction in biliary tract in hilum of liver which non-surgical procedures were not successful, so hepatojejunostomy might be more effective.

Keywords: ERCP; Biliary obstruction; PTBD; Cholangiocarcinoma; Unresectable

\section{Introduction}

Most patients with malignant obstruction of the biliary tract due to cholangiocarcinoma, gallbladder carcinoma and recurrent gastric cancer are not potentially amenable to surgical curative therapy. Malignant obstructive jaundice is associated withpoor survival and morbidities affecting patients' quality of life $[1,2]$. Therefore palliative therapy is required to provide relief from jaundice and pain in the remaining life time $[3,4]$. Non-surgical procedures used to eliminate obstruction due to the place of tumor and type of the disease are ERCP and stenting, percutaneous transhepatic biliary drainage, external and internal stenting which may be unsuccessful $[5,6]$.

Common available Surgicalpalliations performed to provide adequate biliary drainageare segment III cholangiojejunostomy, transtumoral drainage and palliative local resection of tumor [711]. Studies revealed that patients receiving surgical treatment have a longer survival and better quality of life compared to the patients underwent nonsurgical palliative therapies $[12,13]$. Despite main advantages of surgical bypass, high early postoperative morbidity and mortality and complications due to external biliary drainage such as fluid and electrolyte imbalance, loss of bile, dislocation and obstruction of external catheter have to be considered [14,15]. Among surgical techniques, segment III is more favorable, but requires high degree of expertise [16]. In the current study we introduce a simple surgical procedure and investigate its feasibility and efficacy in alleviation of obstructive jaundice.

\section{Patients and Method}

\section{Patients}

During a period of 24 months from 2012 till 2014, 21 cases with severe mechanical cholestasis due to cholangiocarcinoma, gall bladder cancer and recurrent gastric cancer, underwent our new method of palliative surgery. Our study including patients with sufficient volume of segment II and III without metastatic lesion, who had failed ERCP in their history, not eager to do Percutaneous Transhepatic biliary Drainage and had more than three months life expectancy. Before surgery written informed consent was obtained from all patients. Procedures were performed by the same experienced hepatobiliary surgeon.

\section{Surgical method}

After exploring the abdomen, left coronary and left triangular

*Corresponding author: Rezaei MA, Resident of General Surgery, Isfahan University of Medical Sciences, Isfahan, Iran, Tel: +989127786268; Fax: +983136684510; E-mail: rezaei.mohammadtaghi@gmail.com

Received April 25, 2016; Accepted June 29, 2016; Published August 05, 2016

Citation: Sanei B, Kolahdouzan M, Sheikhbahaei S, Janbazi L, Shahabi S, et al (2016) Surgical Palliative Drainage in Un-resectable Malignant Biliary Obstruction J Vasc Med Surg 4: 281. doi: 10.4172/2329-6925.1000281

Copyright: ( $) 2016$ Sanei B, et al. This is an open-access article distributed unde the terms of the Creative Commons Attribution License, which permits unrestricted use, distribution, and reproduction in any medium, provided the original author and source are credited. 
Citation: Sanei B, Kolahdouzan M, Sheikhbahaei S, Janbazi L, Shahabi S, et al. (2016) Surgical Palliative Drainage in Un-resectable Malignant Biliary Obstruction. J Vasc Med Surg 4: 281. doi: 10.4172/2329-6925.1000281

ligaments are divided tomobilizeleft hemiliver. Surgeon`s assistant holds and firmly compressessegment III between the hands to control bleeding. In this step, a small region with surface diameter of 2-3 centimeters anda depth of 1.5-2 centimeters is removed by cautery. Sites of bleeding and bile leakage could be visualized. In cases thatbleeding is from portal triad in order to avoid closing duct, the surgeon locate a feeding tube size 5 or bigger inside the duct according to the size of the duct, and then bleeding from hepatic artery and portal vein is controlled with prolene 6/0. After completely stopping the bleeding and according to the amount, which has been removed usually the cut surface of 2 or 3 small biliary ducts can be identified (Figure 1). If there areless than 2 small ducts more liver tissue will be excised. Thus, considering the diameter of the ducts, feeding tubes at least number 5 with side holes aretentatively inserted inside, and guided through the liver toreach the large ducts. A Roux-en-Y loop of the beginning of jejunum isfashioned afterwards. A single layer anastomosis is accomplished, suturing all layers of jejunum to the liver capsule using PDS 6/0 (Figure 2). Then tubes are fixed to the gut by PDS/5-0 and the outermost layer is anastomosed to the liver capsule separately (Figure 3 ).

\section{Outcomes and statistical analysis}

After the operation patients monitored for the outbreak of cholangitis, anastomosis leakage and pruritus. Bilirubin checked in three period of time, at first, $4^{\text {th }}$ and $6^{\text {th }}$ weeks after operation. The results are presented as mean $\pm \mathrm{SD}$. For statistical analysis chi-square test and paired-T test were used. P-value less than 0.05 was considered statistically significant (Table 1).

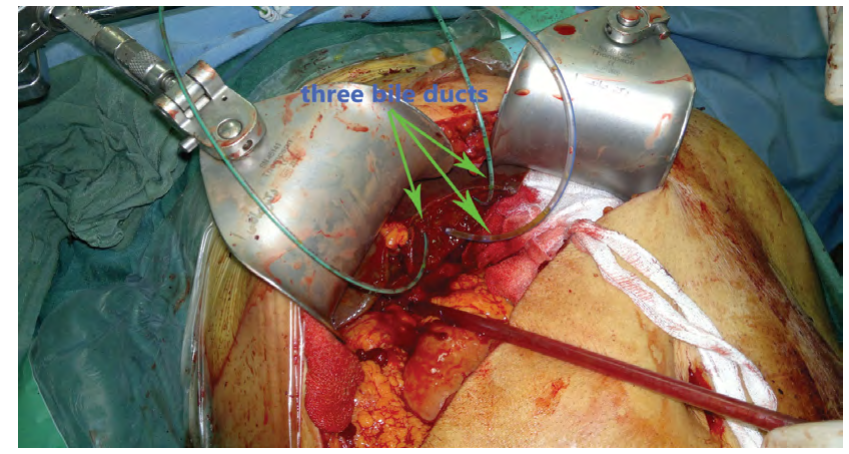

Figure 1: Three bile ducts appear after resection of some part of liver tissue in segment III.

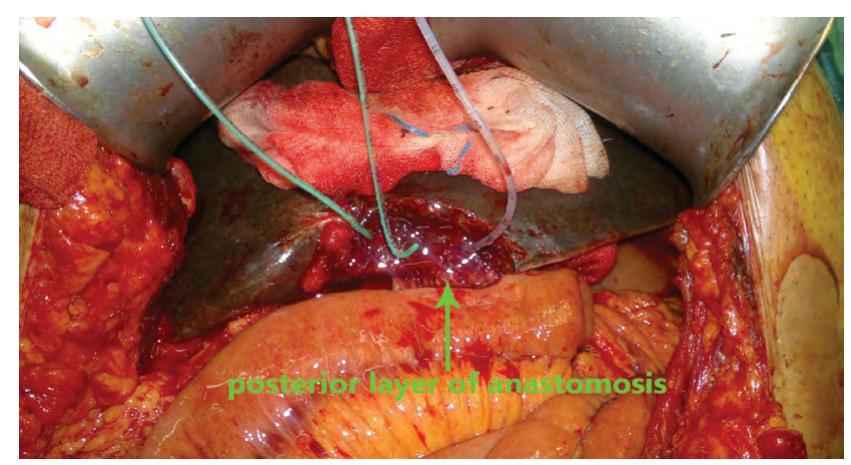

Figure 2: Posterior layer of hepatojejunostomy.

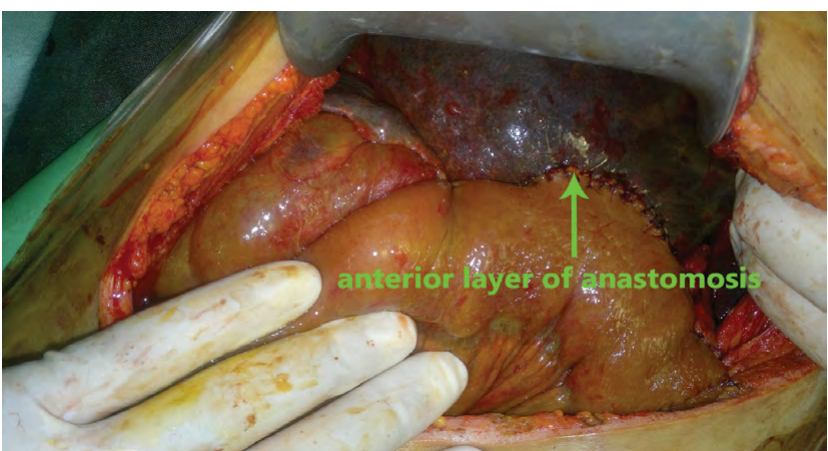

Figure3: Anterior layer of hepatojejunostomy.

\begin{tabular}{|l|c|}
\hline Age $($ Mean \pm SD) & $64.6 \pm 8$ \\
\hline Gender (M/F) & $14-J u l$ \\
\hline Cause of obstructive jaundice & $14(66.6 \%)$ \\
\hline Cholangiocarcinoma & $5(23.8 \%)$ \\
\hline Gall bladder cancer & $2(9.5 \%)$ \\
\hline Recurrent gastric cancer & \\
\hline Cause of un-resectability & $5(23.8 \%)$ \\
\hline Right lobe metastasis & $16(76.2 \%)$ \\
\hline Local invasion & \\
\hline
\end{tabular}

Table 1: Patients' baseline characteristics.

\section{Results}

Biliary decompression was successfully achieved by the new technique in all included subjects including 14 males and 7 females. The mean age of patients was $64.6 \pm 8$ (range 50 to 81 years). All the patients had severe mechanical cholestasis due to cholangiocarcinoma $(\mathrm{n}=14,66.6 \%)$, gall bladder cancer $(\mathrm{n}=5,23.8 \%)$ and recurrent gastric cancer $(n=2,9.5 \%)$. None of the patients had experienced former surgeries in order to decompress cholestasis. Five out of 21 studied patients were not eligible to undergo curative surgeries because of right lobe metastasis and 16 cases due to local invasion in 8 patients (38.1\%), no communication between right and left hepatic duct existed. Mean Bilirubin level prior to surgery was $22.4 \pm 4.1$. Pain and fever due to cholangitis was observed in 4 patients.

The mean time of operation was $233 \pm 32 \mathrm{~min}$. Bilirubin level was measured before the surgery and the $1^{\text {st }}, 4^{\text {th }}$ and $6^{\text {th }}$ weeksafter. Our analysis showed that mean bilirubin level decreased significantly during 6 weeks $(\mathrm{p}<0.001)$ and 17 patients $(94.4 \%)$ had bilirubin below 5 in 6 th week. Eighteen patients $(85.7 \%)$ suffered from pruritus before the operation meanwhile 3 patients complained of itching after the $\mathrm{c}$. The main complication, cholangitis was seen in 3 patients (14.3\%) who had tumoral invasion to the right and left hepatic duct with no communication between. Myocardial infarct happened in 2 patients in early postoperative days. In 1 patient sepsis was developed and caused the patient admitted in ICU. Bile leakage occurred just in one patient $(4.8 \%)$. The 30 -day mortality rate was $14.3 \%(3 / 21)$. Fifteen patients were alive after 3 months from procedure and only 10 patients survived more than 8 months. There was no significant relation between thecauseof mechanical cholestasis and post-operative cholangitis. In addition, prevalence of cholangitis was not significantly higher in metastatic patients $(\mathrm{P}=0.612)$ [16-20]. 


\section{Discussion}

The prognosis of patients suffering from malignant hilar tumor is usually poor. Unfortunately there is limited choice of receiving curative therapyin these patients as they present with surgically unresectable and invasive tumors at the time of diagnosis. These tumors are usually slow growing and patients die from cholangitis and hepatic failure before distant metastasis [1,2]. Alternative cancer therapies such as chemotherapy and radiotherapy are not effective, because patients with high bilirubin level could not benefit from chemotherapy and radiotherapy doesn't help lengthening survival and improving symptoms [1-3]. Thus, the patients with advanced un-resectable tumors should undergo palliative therapy like biliary duct decompression in order to relieve pruritus and cholestasis. Treatment of obstructive jaundice leads to dramatic improvement in quality of life of the affected patients [21-29].

Interventional procedures reported as first-line treatment for biliary system obstruction in patients with primary un-resectable hilar tumors. The non-surgical methods like Endoscopic Retrograde Cholangiopancreatography (ERCP) and percutaneous transhepatic biliary drainage (PTBD) could be effective in patients with biliary system obstruction. Despite lower initial morbidity and mortality related with Endoscopic treatment, more frequent late biliary complications (e.g. clotting of the stent) are observed in this procedure and surgical palliation like hepaticojejunostomy seems to have better long-term results than endoscopic stenting. So for patients with life expectancy of greater than 6 months, it is recommended to perform surgical biliary bypass. It has been shown thatsurgical palliation increases patients' quality of life in greater extension as compared to palliative biliary stenting [23-25]. In addition, high frequency of recurrence and cholangitis in non-surgical palliation requiring further interventions [1].

It seems that adequate drainage is provided by this technique, as jaundice and pruritus were relieved in most of our studied patients. Clinically symptoms' palliation is resulted from at least one half of liver drainage. Superiority of this technique is that the site of bile ducts identified in parenchymal splitting is far from location of hilar tumors, therefore; possibility of being invaded by tumor is rare and it is confirmed with low rate of symptom recurrence in our study. The only cases who were still annoyed with pruritus postoperatively were the ones with occlusion of the draining duct of segment (cholangiocarcinoma). In these patients, sufficient drainage of bile was not achieved in order to improve pruritus (Table 2).

Some procedures have been introduced for decompression of biliary tree to date. The principle of our new method was first described by Longmire and Sanford in 1948 which exposes the dilated ducts by parenchymal resection and placement of two or more internal stents. It has been modified afterwards by Soupault and Couinaud which was based on extra-hepatic dissection of segment III bile duct through the round ligament [1].

Previous studies indicated thatsurgical palliative procedures had significant lower 30-day mortality in contrast with nonsurgical palliative procedure [30-32]. Greater survival after surgical decompression is compared to that of endoscopic stenting or percutaneous trans-hepatic biliary drainage. The method used in this study showed that the mortality rate was $14.28 \%$ (3 patients out of 21) which was in accordance with the previous studies including $11.6 \%$ reported in Aurangzeb, 9\% reported in Schlitt et al. study and 21\% reported in Yeung et al. study $[33,34]$. Biliary leakage was reported as

\begin{tabular}{|l|c|}
\hline Pruritus (N) & $18(85.7 \%)$ \\
\hline Before surgery & $3(14.3 \%)$ \\
\hline After surgery & \\
\hline Cholangitis (N) & $4(19.0 \%)$ \\
\hline Before surgery & $3(14.3 \%)$ \\
\hline After surgery & \\
\hline Bilirubin level (Mean \pm SD) & $22.4 \pm 4.1$ \\
\hline Before surgery & $14.7 \pm 4.1$ \\
\hline $1^{\text {st }}$ week after surgery & $6.7 \pm 2.3$ \\
\hline $4^{\text {th }}$ week after surgery & $3.7 \pm 1.2$ \\
\hline $6^{\text {th }}$ week after surgery & \\
\hline $30-$ day postoperative complications & $2(9.6 \%)$ \\
\hline MI & $1(4.8 \%)$ \\
\hline Bile leakage & $1(4.8 \%)$ \\
\hline Sepsis & $3(14.3 \%)$ \\
\hline Death within 30 days postoperative & \\
\hline
\end{tabular}

Table 2: Pre and post-operation sign and symptoms, complications and surviva related to surgery.

one of the most common complications in patients underwent segment III intrahepatic cholangiojejunostomy, which affects $23 \%$ of patients and impact on patients' survival adversely [35].

The bilirubin level was fortunately decreased progressively in the first, $4^{\text {th }}$ and $6^{\text {th }}$ postoperative weeks. The previous study revealed that the elevated bilirubin significantly affects the morbidity and mortality after biliary tract surgery [36,37]. One of the important outcomes, which palliative surgery aimed, ischolangitis. In this method, the rate of cholangitis incidence was $16.7 \%$ vs. $19 \%$ reported in the study done by in Guthrie et al. in surgically drained cases [38]. It seems there is not much different in the rate of cholangitis occurrence in different surgical methods.

Consequently, this method is acceptable and even that it may be easier technique. It can be used in patients with un-resectable obstruction of the extrahepatic bile duct and those whom experienced failed non-invasive methods. More prospective studies require comparing this technique with other surgical techniques.

\section{Conclusion}

It seems to be very difficult to eliminate the obstruction due to un-resectable mass in the hilum of liver. Our study introduced a new technically simple method, which does not require expertise as much as previous surgical palliative therapies and also had same mortality rate and probably fewer complications. Itcould be considered as an alternative way in patients who failed biliary drainage procedures.

\section{Acknowledgements}

We would like to thank staff of general surgery department in Alzahra hospital, Isfahan University of Medical Science, for support and allowing us to work on this subject.

\section{Conflict of Interest}

The authors declare that there is no conflict of interest in authorship or contribution of this article.

\section{References}

1. Yeo CJ, McFadden DW, Pemberton JH, Peters JH, Matthews JB (2012) Shackelford's Surgery of the Alimentary Tract: Set: Elsevier Health Sciences.

2. Forsmo HM, Horn A, Viste A, Hoem D, Ovrebo K (2008) Survival and an overview of decision-making in patients with cholangiocarcinoma. Hepatobiliary Pancreat Dis Int 7: 412-417. 
Citation: Sanei B, Kolahdouzan M, Sheikhbahaei S, Janbazi L, Shahabi S, et al. (2016) Surgical Palliative Drainage in Un-resectable Malignant Biliary Obstruction. J Vasc Med Surg 4: 281. doi: 10.4172/2329-6925.1000281

3. Lai E, Lau S, Lau W (2013) Palliative Surgical Treatment. Hilar Cholangiocarcinoma. Springer: 291-296

4. Khan SA, Davidson BR, Goldin R, Pereira SP, Rosenberg WM, et al. (2002) Guidelines for the diagnosis and treatment of cholangiocarcinoma: consensus document. Gut 51: 1-9.

5. Kunyakham W, Mairiang P, Sangchan A, Sawadpanitch K (2015) Comparison of Quality of Life in Patients with Hilar Cholangiocarcinoma Pre-and PostTreatment. Thai J Gastroenterol 16: 10-15.

6. Liu CL, Lo CM, Lai EC, Fan ST (1998) Endoscopic retrograde cholangiopancreatography and endoscopic endoprosthesis insertion in patients with Klatskin tumors. Arch Surg 133: 293-296.

7. Soupalt R (1957) In: Couinaud C (ed.) Sur unprocede nouveau de derivation biliareintrahepatiqueles cholangio-je'junostomiesgauchessans sacrifice he'patique 65: 1157-1159.

8. Bismuth $\mathrm{H}$, Corlette MB (1975) Intrahepatic cholangioenteric anastomosisin carcinoma of the hilus of the liver. Surgery, Gynecologyand Obstetrics 140 $170-178$

9. Blumgart LH, Kelley CJ (1984) Hepaticojejunostomy in benign and malignan high bile duct stricture: approaches to the left hepatic ducts. $\mathrm{Br} J$ Surg 71 : 257-261.

10. Terblanche J, Saunders SJ, Louw JH (1972) Prolonged palliation in carcinoma of the man hepatic duct junction. Surgery 71: 720-731.

11. Lillemoe KD, Cameron JL (2000) Surgery for hilar cholangiocarcinoma: the Johns Hopkins approach. J Hepatobiliary Pancreat Surg 7: 115-121.

12. Gazzaniga GM, Filauro M, Bagarolo C, Mori L (2000) Surgery for hilar cholangiocarcinoma: an Italian experience. J Hepatobiliary Pancreat Surg 7: 122-127.

13. Figueras J, Llado L, Valls C, Serrano T, Ramos E, et al. (2000) Changing strategies in diagnosis and management of hilar cholangiocarcinoma. Liver Transpl 6: 786-794.

14. Launois B, Reding R, Lebeau G, Buard JL (2000) Surgery for hilar cholangiocarcinoma: French experience in a collective survey of 552 extrahepatic bile duct cancers. J Hepatobiliary Pancreat Surg 7: 128-134.

15. Gerhards MF, van Gulik TM, de Wit LT, Obertop H, Gouma DJ (2000) Evaluation of morbidity and mortality after resection for hilar cholangiocarcinoma a single center experience. Surgery 127: 395-404.

16. Singhal D, van Gulik TM, Gouma DJ (2005) Palliative management of hilar cholangiocarcinoma. Surg Oncol 14: 59-74.

17. Klatskin G (1965) Adenocarcinoma of the hepatic duct at its bifurcation within the porta hepatis. An unusual tumor with distinctive clinical and pathological features. Am J Med 38: 241-256.

18. Okuda K, Kubo Y, Okazaki N, Arishima T, Hashimoto M, et al.(1977) Clinica aspects of intrahepatic bile duct carcinoma including hilar carcinoma:a study of 57 autopsy-proven cases. Cancer 39: 232-246.

19. Pitt HA, Nakeeb A, Abrams RA, Coleman J, Piantadosi S, et al. (1995) Perihila cholangiocarcinoma. Postoperative radiotherapy does not improve survival. Annals of surgery 221: 788-796.

20. Palmer WC, Harnois DM (2015) Cholangiocarcinoma. Complications of Cirrhosis: Springer: 219-227.

21. Abraham NS, Barkun JS, Barkun AN (2002) Palliation of malignant biliary obstruction: a prospective trial examining impact on quality of life. Gastrointest Endosc 56: 835-841.

22. Felix R, Langer $R$ (1992) Interventional non-surgical drainage techniques in proximal bile duct tumors. Chirurg 63: 535-538.
23. van Heek NT, van Geenen RC, Busch OR, Gouma DJ (2002) Palliative treatment in "peri"-pancreatic carcinoma: stenting or surgical therapy? . Acta Gastroenterol Belg 65: 171-175

24. Taylor MC, McLeod RS, Langer B (2000) Biliary stenting versus bypass surgery for the palliation of malignant distal bile duct obstruction: a meta-analysis. Liver Transpl 6: 302-308.

25. Stumpf M, Kasperk R, Bertram P, Truong S, Schumpelick V (2001) Role of surgical biliary bypass for palliation of pancreatic cancer - a retrospective study of 107 cases. Zentralbl Chir 126: 913-916.

26. Boulay BR, Parepally M (2014) Managing malignant biliary obstruction in pancreas cancer: choosing the appropriate strategy. World J Gastroenterol 20 9345-9353.

27. Glazer ES, Hornbrook MC, Krouse RS (2014) A meta-analysis of randomized trials: immediate stent placement vs. surgical bypass in the palliative management of malignant biliary obstruction. J Pain Symptom Manage 47 307-314.

28. Polydorou AA, Cairns SR, Dowsett JF, Hatfield AR, Salmon PR, et al. (1991) Palliation of proximal malignant biliary obstruction by endoscopic endoprosthesis insertion. Gut 32: 685-689.

29. Soupault R, Couinaud C (1957) New procedure for intrahepatic biliary shunt: left cholangiojejunostomy without hepatic sacrifice. Presse Med 65: 1157-1159.

30. Shimada H, Niimoto S, Matsuba A, Nakagawara G, Kobayashi M, et al. (1987) Experience with intrahepatic cholangiojejunostomy for unresectable carcinoma of the hepatic hilus. International surgery $73: 1-5$

31. Lee TY, Cheon YK, Shim CS, Cho YD (2012) Photodynamic therapy prolong metal stent patency in patients with unresectable hilar cholangiocarcinoma. World J Gastroenterol 18: 5589-5594

32. Lai EC, Chu KM, Lo CY, Fan ST, Lo CM, et al. (1992) Choice of palliation for malignant hilar biliary obstruction. Am J Surg 163: 208-212.

33. Aurangzeb M (2011) The longmire procedure: is it worthwhile? Journal of Postgraduate Medical Institute (Peshawar-Pakistan) 20.

34. Schlitt HJ, Weimann A, Klempnauer J, Oldhafer KJ, Nashan B, et al. (1999) Peripheral hepatojejunostomy as palliative treatment for irresectable malignant tumors of the liver hilum. Ann Surg 229: 181-186.

35. O'Suilleabhain CB, Madhavan KK (2004) A modification of segment III intrahepatic cholangiojejunostomy. Am J Surg 187: 131-133.

36. Pitt HA, Cameron JL, Postier RG, Gadacz TR (1981) Factors affecting mortality in biliary tract surgery. Am J Surg 141: 66-72.

37. Su CH, P'eng FK, Lui WY (1992) Factors affecting morbidity and mortality in biliary tract surgery. World J Surg 16: 536-540.

38. Guthrie CM, Haddock G, De Beaux AC, Garden OJ, Carter DC (1993) Changing trends in the management of extrahepatic cholangiocarcinoma. $\mathrm{Br}$ J Surg 80: 1434-1439. 